\title{
DO CONTEXTUAL FACTORS MATTER IN THE ADOPTION OF PROACTIVE ENVIRONMENTAL MANAGEMENT PRACTICES IN HOTELS? THE MANAGER'S PERSPECTIVE
}

\author{
Ayesha L. Kotuwage \\ Graduate School of Management, Postgraduate Centre (PGC), Management and Science \\ University (MSU), Malaysia \\ Mazuki Jusoh \\ Graduate School of Management, Postgraduate Centre (PGC), Management and Science \\ University (MSU), Malaysia
}

\section{S.M. Ferdous Azam}

Graduate School of Management, Postgraduate Centre (PGC), Management and Science University (MSU), Malaysia

\section{Sepali Sudasinghe}

Management and Science University Colombo Learning Centre, Sri Lanka

\begin{abstract}
The aim of this study is to investigate the proactive environmental management practices by graded hotels in Sri Lanka and how these practices vary according to hotel ownership, size and star category. The study used stratified random sampling and the sample consisted of 314 managers from graded hotels in Sri Lanka. Using a self- administrated questionnaire, the data of this study was collected from hotel managers and owners from different categories of hotels. The results of t-test and analysis of variance suggest that proactive environmental management practices of hotels vary by hotel category, size and ownership. More precisely, chain- owned, higher- graded (5-4 star) and medium-sized hotels were at the forefront of the adoption of proactive environmental management practices.
\end{abstract}

KEYWORDS: proactive environmental management practices, hotel ownership, hotel grade, hotel size, Sri Lanka

\section{INTRODUCTION}

During the past few decades, environmental issues have attracted significant attention due to higher levels of environmental degradation that threaten to completely alter the earth and leads to severe problems around the world (e.g : pollution, global warming, ozone layer depletion, acid rain, natural resource depletion, overpopulation, waste disposal, deforestation and loss of biodiversity). Hence, the World Commission on Environment and Development (WCED, 1987) has come up with a resolution that would help to reduce negative environmental impact by defining sustainable development which emphasize the important of environmental sustainability. Thus, business organizations have progressively integrated environmental management as a part of their corporate strategic plan (Gustafsson, Hermelin \& Smas, 2018; 
Baumgartner \& Rauter, 2016; Testa et al., 2015; Banerjee et al., 2003). Moreover, researches have revealed that the proactive environmental initiatives and practices are considered an instrument for high performance levels and to gain competitive advantage for the organization (Liu, 2019; Marchi, Maria, \& Micelli, 2013; Molina-Azorı'n, Claver-Corte', Pereira-Moliner, \& Juan Jose, 2009).

The World Travel and Tourism Council (WTTC) have mentioned travel and tourism as one of the world's largest and profitable industries. According to them, the industry generates more than 319 million jobs worldwide and contributes $10.4 \%$ (US\$8.8 trillion) of the world GDP (WTTC, 2018). Furthermore, according to United Nations Environmental Programme (UNEP) and World Tourism Organization (UNWTO) tourism is ranked as the third largest export in global export (UNEP and UNWTO, 2018). Meanwhile, tourism is identified as a resourceintensive industry (Mbasera et al., 2018; Lu \& Nepal, 2009) and the earth's natural resources can be considered as major attractions for majority of global tourism (Farrell \& Runyan, 1991). United Nations Environmental Program-UNEP (2001) reveals the uncontrolled traditional tourism makes potential threats to the worlds' natural environment in various ways such as deforestation, soil erosion, increased pollution, over utilization of electricity and water resources, discharge sewage into the sea and water streams, loss of natural habitat and increased pressure on endangered species (UNEP, 2001).

The hotel sector of the tourism industry comprises of a variety of activities that have a significant impact on the environment. Hotel activities includes a large number of operations and each of these operations consumes relatively large amounts of energy, water, food, paper and other resources as well as generates significant amount of waste. Chou (2014) has mentioned the impact of the global growth of tourism on the environment has become a foremost issue in the hospitality. Examining environmental management practices of the hotel sector is vital due to several reasons; the industry has a huge impact on the environment, the growing environmental consciousness of tourists and the nature of this business is dependent on the natural and man-made environment (Carmona- Moreno et al., 2004; Scholz \& Voracek, 2016).

Sri Lanka has been booming and ranked as one of the top tourist destinations in the world for the past few years (Fernando et al., 2016). The one of the major reasons behind it is its location. Sri Lanka offers a superfluity of options for tourists including beach destinations, favorable climate, rich cultural heritage, national parks and wildlife (Lai, 2002; Fernando et al., 2016). Due to significant growth in the industry, one of the most prestigious global travel publications in the world "Lonely Planet", has ranked Sri Lanka as the Best Country to Visit in the year 2019 (BOI Sri Lanka, 2018). Sri Lanka ended the year 2018 with 2.33 million tourists. The total number of international tourist arrivals to Sri Lanka during March 2019 was 244,328. In comparison to March last year, there was a growth of $4.7 \%$ when the arrivals were 233,382 (Monthly tourist arrivals report -Sri Lanka Tourism Development Authority March, 2019). Furthermore, tourism has shifted from the 4th place (in 2013) to the 3rd place (in 2014 and remain so up to date) in foreign exchange earnings to the national economy of Sri Lanka (Sri Lanka Tourist Development Authority, 2018). Due to this significant growth, there is potential to increase environmental related hazard, if the industry is not paying sufficient attention towards environmental impact as well as environmental management. Meanwhile, hotels' environmental management practices in Sri Lanka are not at a satisfactory level, and large hotels' environmental performances are relatively better than smaller ones (Wickramasinghe, 
2016). Literature has emphasized that by paying significant attention on environmental issues and investing on green tourism can reduce the cost of resources that they used for, such as, energy, water, and waste. This can also conserve cultural heritage and enhance the value of biodiversity by protecting ecosystems (UNWTO, 2018). Present day the environmental friendliness of hotels, which express through their environmental management has become one of the significant competitive forces of the hotel business. Because of not only tourists demand over environmentally friendly hotels, but this also show their corporate social responsibility over the natural environment and the nature of the business depending on natural and man made environment. Hence, in order to evaluate the nature and the degree of hotel's proactive environmental practices, this study analyzes the influence of firm's characteristics on environmental management practice. Although, many studies have proved how different stakeholders both internal and external as well as firms' internal competencies (resources) influence firms' adoption of proactive environmental practices (Russo \& Perrini, 2010; Hart \& Dowell, 2011; Singh et al., 2014), there are only a limited number of studies that examine the impact of firm's characteristics such as hotel size, ownership and grade on environmental management practices in hotel industry and most of the studies relating to environmental management have been conducted in developed countries (Singh et al., 2014). Hence, the purpose of this present study is to examine current proactive environmental practices and the impact of hotel's contextual factors on adoption of proactive environmental practices in hotels of Sri Lanka. And to examine whether the degree of adoption of proactive environmental practices vary according to hotel's contextual factors such as size, category and ownership.

Hence, this study addresses four research questions: (1) To what extent does hotels adopt protective environmental management practices? (2) Is chain- owned hotels' environmental proactivity is higher than non- chain owned hotels? (3) Does adoption of protective environmental practices vary according to size of the hotel? (4) Are the proactive environmental practices in higher graded hotels greater than the lower graded hotels?

\section{LITERATURE REVIEW}

\section{Proactive Environmental Management Practices in Hotels}

Conserving natural environment and its quality has become one of the important concern of business activities of the hotel industry (Kim et al., 2012; Erdogan \& Tosun, 2009). Environmental management practices in hotels refers to the extent to which that a hotel seek to implement environmental initiatives (Park et al., 2014). These practices can vary from most advance 'proactive' practices to least committed 'reactive' practices (Carmona-Moreno et al., 2004). Furthermore, proactive environmental management practices and initiatives of the organization are considered as the commitments that go beyond the minimum level of legal compliance. Cramer in 1998 defined environmental management as "the study of all the technical and organizational activities aimed at reducing the environmental impact caused by a company's operations. These technical and organizational environmental initiatives can be diverse according to the nature of the industry, organizational characteristics and degree of the environmental impact (Carmona-Moreno et al., 2004). As Carmona-Moreno et al. (2004) reveals, the firms' proactive environmental strategies are not necessarily relate with economic performance but there is a strong association with firms' environmental performance. 
Furthermore, firm's characteristic has play an important role in the adoption of environmental management initiatives (Singh et al., 2014).

\section{Impact of Hotel's Contextual Factors}

\section{Hotel Size}

Díaz-Garrido et al. (2016) have identified the firm size as one of the influencing factor of the implementation of environmental practices. This is because, the larger firms have enough resources to carry out their environmental management practices and they have more pressure from their stakeholders (Gonz alez-Benito \& Gonz alez-Benito, 2006).Moreover, research on organizations and environment has revealed that larger firms are more likely to implement proactive environmental strategies (Sharma, 2000; Etzion, 2007) while smaller firms show less progress in the environmental involvement (Florida, 1996; Alvarez et al., 2001). Similarly, Clark (2000) stated that small and medium-sized enterprises have difficulties in adopting advanced environmental management programs due to lack of financial, human and other resources. Furthermore, according to literature, some studies have used firm size as independents variables, while others considered firms' size as control variable (Vachon \& Klassen, 2006). Literature indicates that firm size has a significant effect on the degree of proactiveness, with larger organizations being more likely to adopt proactive environmental practices (Arago'n-Correa, 1998; Buysse \& Verbeke, 2003; Russo \& Fouts, 1997; Sharma, 2000). Large hotels will be more encouraged to adopt environmental proactive strategies than small ones (Carmona- Moreno et al., 2004). Hotel size is measured by the number of hotel rooms it has. The size of the hotel expresses the effect of scale economies and the availability of resources on the implementation of EMPs. There is a great deal of empirical evidence supporting the relevance of firm size matters in the environmental debate, with larger firms being more proactive (Alvarez Gil et al., 2001; Chan, 2005; Claver-Cortes et al., 2007; Gonzalez-Benito \& Gonzalez- Benito, 2006). Moreover, Wickramasinghe (2016) has conducted a study on adoption of environmental practices of hotel in Sri Lanka and revealed that large hotels are more inclined to proactive environmental practices than small hotels.

\section{Hotel Ownership}

A chain hotel is a 'hotel that is part of a series or of a group of hotels operated by the same company or owner' (Collins English Dictionary, 2017). Hotels which are doing their businesses independently known as 'independent hotels' while 'chain hotel' is an administration company, which manages a number of hotels having the same name but being located in different areas' (Glossary for hotel revenue management, 2017). Furthermore, these chains can be local chain hotels and international chain hotel (Carmona-Moreno et al., 2004). The literature suggests that international chain hotels are more likely to implement environmental strategies due to the effects of economies of scale, marketing experience in markets where green differentiation is possible, and the possible transfer of environmental knowledge among affiliates (Wickramasinghe, 2016; Alvarez Gil et al., 2001; Ayuso, 2006; Bohdanowicz, 2006; CarmonaMoreno et al., 2004). The chain hotels always practice standardized hotel management which allows them to keep their reputation and taking advantage of economies of scale. These practices lead to an increase in the efficient use of resources (Brown and Dev, 1999). Therefore, in order to respect for the environment, the chain may carry out certain minimum or common norms regarding environmental protection. These minimum norms can make more difficult or 
easy for the chain-affiliated hotels to adopt and promote a more proactive environmental practices (Carmona-Moreno et al., 2004). Wickramasinghe's (2016) findings from hotel in Sri Lanka revealed that chain affiliated hotels' environmental orientation is higher than independent owned hotels. This suggested that there is a need for motivating the independent hotels to adopt proactive environmental management practices.

\section{Hotel Category}

The star classification of a hotel is a significant determinant of the adoption of different environmental management practices. Wickramasinghe (2016) found that, when a hotel becomes star-classified, the number of water management practices and other environmental measures tend to increase than hotels which are not belong to star graded classification. The category (4- or 5-star) and sun-and-sand tourism establishments are generally more environmentally proactive than their counterparts of lower category or dominated by other type of clientele (Alvarez Gila et al., 2001).Mensah's (2006) found that 3-5 star category hotels adopt more environmental practices than 1-2 star category. It should be noted that nearly half the sample of 3-5 star hotels in this study were chain-affiliated. Erdogan (2007) findings in the Turkish hotel industry support Mensah's (2006) findings. Sustainable technologies adopted in higher star category hotels include energy saving technologies, keycard control system and solar water heaters, to some extent than lower categories.

\section{METHODOLOGY}

\section{Sample and Data Collection}

The study used a survey questionnaire to collect information on hotel's proactive environmental management practices and its characteristics. This study focused on star graded hotels in Sri Lanka and the target population was top-level hotel managers of 156 graded hotels. The study has distributed 500 questionnaires among managers and owners of star graded hotels and returned 338. Among them, 314 were usable and the response rate was $67 \%$. The hotel top managers and owners were chosen for the study as they are the key decision makers who are familiar with the hotels' environmental management practices. The hotels surveyed were selected using stratified random sampling based on hotel category.

\section{Measures}

The study consists of both observable variables and latent constructs. The proactive environmental management practices variable was the latent construct (continuous) which was measured by using a five-point Likert scale (with anchors of 5- being strongly agree/very great extent; 1-being strongly disagree/ not at all) and hotel's contextual factors (size, grade and ownership) were the observed variables. All measures encompassed in the questionnaire were developed base on previous literature. Prior to the data collection for the main survey, the questionnaire was reviewed by a panel of industry experts and scholars in order to assess the validity of the items in the questionnaire.

\section{Proactive Environmental Management Practices (PEMP)}

In this study, adoption of proactive environmental practices refers to the extent to which a hotel seek to adopt proactive environmental practices. The study focuses on two dimensions of 
proactive environmental practices: technical (operational) practices and system (organizational) practices (Molina- Azorin et al., 2009). Operational practices are define as technical activities that used to reduce the negative impact on the natural environment such as energy and water saving activities, and waste management) while system practices (such as provides training to employees on environmental issues, facilitates customer collaboration in environmental protection, and gives compensation to employees who have environmental initiatives) are organizational activates which support operational environmental practices (Park et al., 2014). Each scale for basic practices and advanced practices had five items. Respondents were asked to indicate the extent to which their hotels are involved in both basic and advanced practices on a 5-point scale where 1 is "not at all", 2 is "limited extent", 3 is "moderate extent", 4 is "great extent" and 5 is "very great extent".

\section{Hotels' Contextual Factors}

Hotel size, grade and type of ownership were observed variables. The hotel size is measured by determining the number of rooms in the hotel- categorized as large (more than 100 rooms), medium (between 25-100 rooms) and small scale hotels (consisted less than 25 rooms). The ownership of hotel is measured with two categories as chain - owned hotels and independent hotels. Hotels grades were categorized under five categories- five star hotels to one star hotels.

\section{Method}

The current study uses descriptive statistics, independent sample t-test and one-way ANOVA to reach its objectives. In examining as to whether there exists any discrepancy of the adoption of proactive environmental management practices among different groups by ownership, hotel category (star grade) and size, independent sample t-test and one-way ANOVA with post hoc tests using Tukey's test were conducted for each of the select contextual factors (ownership, star grade and size). The independent sample t-test was used to test if there is a difference in a measured characteristic between two groups of cases while the one-way analysis of variance (ANOVA) is used to determine whether there are any statistically significant differences between the mean scores on the dependent variable across more than two independent (unrelated) groups (Pallant, 2016). The ANOVA is the notion of variance. The basic procedure is to derive two different estimates of population variance from the data, then calculate a statistic from the ratio of these two estimates (between groups and within groups variance). The F-ratio is the ratio of between-groups variance to within-groups variance. A significant Fvalue indicates that the population means are probably not equal. And Levene's test is used to determine if the scores in each group have homogenous variances. Before independent sample t-test and ANOVA were performed, the data was ensured to meet the necessary assumptions. The two assumptions of concern were population normality and homogeneity of variance. 


\section{RESULTS AND DISCUSSION}

\section{Sample Characteristics}

The average age of respondents was 41 years and they had an average of 15 years of career experience in the hotel industry. Among 314 managers, 24\% and 13\% had secondary and vocational / diploma qualification respectively. A majority $38 \%$ had professional qualification, $21 \%$ had degree and $4 \%$ had postgraduate degree. Only two managers were qualified with PhDs. Regarding gender, $84 \%$ managers were male and $16 \%$ were female. The majority of respondents in this study were 'Heads of the Departments' (70\%) and 22\% of respondent were senior managers (CEO, GM, President and Senior Executives) and 8\% were working as owner manager. Among them, 27\% were from five-star hotel grade, $24 \%$ from four-star grade, $17 \%$ from three-star grade, $21 \%$ ) from two grade hotels and the lowest number of managers from one-star grade hotel, $10.5 \% .40 \%$ of managers reported that they work for chain owned hotels and $60 \%$ belongs to non- chain category. Pertaining to the size of hotel (based on the number of rooms), $41 \%$ managers worked at hotels with more than 100 rooms, $35 \%$ worked in hotels with 26-100 rooms, and the rest of managers (24\%) were working at small scale hotels that consisted less than 25 rooms.

\section{Descriptive Statistics and ANOVA}

The purpose of this study was to determine as to which contextual factors (ownership, size and category) influence the adoption of proactive environmental practices in hotels. In order to assess whether the adoption of proactive environmental practices was influenced by different hotel characteristics, several analyses were conducted (descriptive statistics, independent sample t- test and one- way ANOVA test).

Reliability refers to "the degree to which measures are free from error and therefore yield consistent results across time and across the various items in the instrument' (Zikmund, 2003). The Cronbach's alpha reliability coefficient was calculated for each variable of operational practice and system practices. The Cronbach's alpha coefficient was higher for proactive environmental practices and both operational practice and system practices $(>0.8)$ and showing a soundly good internal consistency of the measurement scales. 
Print ISSN: ISSN 2054-6424(Print), Online ISSN: ISSN 2054-6432(Online)

Table 1: Means for the dependent variables and their items

\begin{tabular}{|c|c|c|c|c|c|c|c|c|c|c|c|}
\hline \multirow[t]{3}{*}{ Items } & \multirow[t]{3}{*}{ Overall } & \multicolumn{10}{|c|}{ Proactive Environmental Practices (Cronbach's alpha 0.84) } \\
\hline & & \multicolumn{2}{|c|}{ Ownership } & \multicolumn{3}{|c|}{ Size } & \multicolumn{5}{|c|}{ Grade/ category } \\
\hline & & Chain & $\begin{array}{l}\text { Non- } \\
\text { chain }\end{array}$ & $\mathrm{S}$ & $\mathrm{M}$ & $\mathrm{L}$ & $1^{*}$ & $2^{*}$ & $3^{*}$ & $4^{*}$ & $5^{*}$ \\
\hline $\begin{array}{l}\text { Operational Practices (OP) } \\
\text { (Cronbach's alpha 0.86) }\end{array}$ & 4.05 & 4.18 & 3.97 & 3.89 & 4.11 & 4.41 & 3.87 & 4.06 & 4.06 & 4.09 & 4.10 \\
\hline $\begin{array}{l}\text { 1.Applies energy-saving } \\
\text { practices }\end{array}$ & 4.03 & 4.15 & 3.96 & 3.81 & 4.11 & 4.06 & 3.73 & 4.08 & 4.19 & 4.05 & 4.00 \\
\hline $\begin{array}{l}\text { 2. Applies water-saving } \\
\text { practices. }\end{array}$ & 4.11 & 4.07 & 4.13 & 4.13 & 4.27 & 4.02 & 4.09 & 4.31 & 4.28 & 4.03 & 3.95 \\
\hline $\begin{array}{l}\text { 3. Has a waste management } \\
\text { practice. }\end{array}$ & 4.15 & 4.34 & 4.03 & 4.04 & 4.05 & 4.25 & 4.18 & 4.15 & 3.89 & 4.17 & 4.29 \\
\hline $\begin{array}{l}\text { 4. Gives priority to purchasing } \\
\text { ecological products } \\
\text { (biodegradable, reusable, } \\
\text { recyclable) }\end{array}$ & 3.70 & 4.07 & 3.57 & 3.44 & 3.80 & 3.85 & 3.39 & 3.57 & 3.70 & 3.95 & 3.94 \\
\hline $\begin{array}{l}\text { 5. Reduces the use of } \\
\text { environmentally dangerous } \\
\text { products }\end{array}$ & 4.21 & 4.27 & 4.02 & 4.06 & 4.24 & 4.18 & 3.94 & 4.22 & 4.25 & 4.23 & 4.26 \\
\hline $\begin{array}{c}\text { System Practices (SP) } \\
\text { (Cronbach's alpha 0.82) }\end{array}$ & 3.52 & 3.70 & 3.45 & 3.29 & 3.61 & 3.58 & 3.16 & 3.58 & 3.50 & 3.52 & 3.50 \\
\hline $\begin{array}{l}\text { 6. Provides training to } \\
\text { employees on environmental } \\
\text { issues }\end{array}$ & 3.89 & 4.27 & 4.17 & 4.06 & 4.34 & 4.18 & 3.94 & 4.22 & 4.25 & 4.23 & 4.26 \\
\hline $\begin{array}{l}\text { 7. Gives compensation to } \\
\text { employees who have } \\
\text { environmental initiatives }\end{array}$ & 3.25 & 3.42 & 3.14 & 2.90 & 3.29 & 3.34 & 3.00 & 3.15 & 3.09 & 3.34 & 3.44 \\
\hline $\begin{array}{l}\text { 8. Uses ecological arguments in } \\
\text { marketing campaigns }\end{array}$ & 3.23 & 3.47 & 3.08 & 2.73 & 3.24 & 3.38 & 2.76 & 3.25 & 2.89 & 3.38 & 3.49 \\
\hline $\begin{array}{l}\text { 9. Facilitates customer } \\
\text { collaboration in environmental } \\
\text { protection (voluntary changing } \\
\text { of towels) }\end{array}$ & 3.72 & 3.71 & 3.73 & 3.69 & 3.94 & 3.60 & 3.55 & 3.92 & 3.89 & 3.53 & 3.71 \\
\hline $\begin{array}{l}\text { 10. Organizes or sponsors } \\
\text { environmental protection } \\
\text { activities }\end{array}$ & 3.60 & 3.85 & 3.43 & 3.25 & 3.63 & 3.69 & 3.00 & 3.57 & 3.64 & 3.60 & 3.83 \\
\hline $\begin{array}{l}\text { Proactive Environmental } \\
\text { Management Practices }\end{array}$ & 3.94 & 3.94 & 3.70 & 3.59 & 3.86 & 3.82 & 3.52 & 3.82 & 3.78 & 3.87 & 3.98 \\
\hline
\end{tabular}

Table 1 shows the descriptive statistics of mean for adoption of proactive environmental management practices. The operational environmental management practice dimension in the construct reported a means score of 4.05 and system practices mean score was 3.52. The mean scores evidenced that hotels were more committed towards operational practices rather than system practices. As shown in Table 1 the mean score of adoption of proactive of environmental practice was 3.94. Hence, the overall mean score for adoption of proactive of environmental practices was varied between moderate extent and great extent scale and it says that hotels environmental practices shows somewhat proactive but not very strong. The descriptive statistics for each item are shown in Table 1 Mean scores ranged from 3.23 to 4.21. The lowest mean score (Mean $=3.23$ ) was obtained for item 5, "Uses ecological arguments in marketing campaigns". The highest mean score $($ Mean $=4.21)$ was obtained for item 8 , "Reduces the use of environmentally dangerous products". 


\section{t-Test PEMP between Chain -Owned and Non-Chain Owned Hotels}

First independent sample t- test was conducted to compare adoption of proactive environmental management practices (PEMP) for chain- owned and non- chain hotels. The independent sample t-test result is shown in table 2 and 3.

Table 2: Group Statistics

\begin{tabular}{llrrrr}
\hline Type of ownership & $\mathrm{N}$ & \multicolumn{1}{c}{ Mean } & \multicolumn{1}{c}{ Std. Deviation } & \multicolumn{1}{c}{ Std. Error Mean } \\
\hline \multirow{2}{*}{ PEMP } & Chain & 123 & 3.9409 & .63269 & .05705 \\
& Non- chain & 191 & 3.7042 & .65661 & .04751 \\
\hline
\end{tabular}

Table 3: Results of Independent Sample t- test

\begin{tabular}{lllllllll}
\hline & & \multicolumn{2}{l}{$\begin{array}{l}\text { Levene's Test for } \\
\text { Equality of Variances }\end{array}$} & & & t-test for Equality of Means & \\
\cline { 3 - 9 } & & F & Sig. & T & Df & $\begin{array}{l}\text { Sig. (2- } \\
\text { tailed) }\end{array}$ & $\begin{array}{l}\text { Mean } \\
\text { difference }\end{array}$ & $\begin{array}{l}\text { Std. error } \\
\text { difference }\end{array}$ \\
\hline PEMP & $\begin{array}{l}\text { Equal variances } \\
\text { assumed }\end{array}$ & .421 & .517 & 3.159 & 312 & .002 & .236 & .080 \\
\cline { 2 - 10 } & $\begin{array}{l}\text { Equal variances } \\
\text { not assumed }\end{array}$ & & & 3.185 & 267.3 & .002 & .236 & .074 \\
\hline
\end{tabular}

As shown in Table 2 and 3, the sample mean for the chain - owned hotels is 3.9409 and the sample mean for non- chain hotels is 3.7042. The p- value for the Levene's test for equality of variance is 0.517 . Since, the p- value is more than 0.05 , equality of variance is assumed. Therefore, for the test of equality of variance, the statistics in the first row in the table 3 was used. The mean difference is 0.236 and the standardized, $t(312)=3.159$. The p-value of the test is less than $0.005(\mathrm{p}=.002)$. These results suggest that there is a difference in PEMP means between the chain - owned and non- chain owned hotels. The PEMP mean for chain hotels is significantly higher compared for the non - chain hotels. Hence, the results suggest that chain - owned hotels are more concerned on adoption of proactive environmental management practices than non- chain hotels.

\section{ANOVA test of PEMP across Hotel Size and Category}

One-way ANOVA was conducted to compare the effect of hotel size (small, medium and large) on the adoption of proactive environmental management practices. The descriptive result presented in table 4 shows that the sample mean for small hotels is 3.5923, 3.8611 for medium hotels and 3.8240 sample mean for large hotels. The results suggested that the PEMP mean for the medium size hotels is higher than the means for either the small and large size hotels. Next up is a test for the homogeneity of variances for hotel size. As can be seen in Table 5, the pvalue for the Levene's test for equality of variance is 0.459 , which is more than 0.05 ( $p>0.05)$. Thus, homogeneity of variance assumption is met. The analysis of variance result in Table 6 shows that the effect of hotel size on proactive environmental management practices was significant: $\mathrm{F}(4,311)=3.163, \mathrm{p}=0.044(\mathrm{p}<0.05)$. Hence, at least one pair of means differ 
significantly. Post hoc test with Tukey test was used to produce multiple comparison between group means (see Table 7). The medium hotels condition is compared against the small hotel condition. The mean difference is .26874 and the p-value is .046 . Because $p<.05$, the difference between the medium and small hotel condition is "significant". The other two mean comparisons (small vs. large and medium vs. large) were not significant because the p-values are above .05 ( $\mathrm{p}=.067$ and .898 respectively). Hence, the results conclude that medium size hotels (with rooms 26-100) shows higher level of proactive environmental management practices than small hotels (rooms less than 25). Other comparisons were not significant.

Finally, One-way ANOVA was conducted to compare the effect of hotel grade (1 to 5 star) on proactive environmental management practices. The descriptive result as presented in table 4 shows that the sample mean for 1 star hotels is 3.5152, 2 star hotels $=3.8200$, 3 star hotels $=$ $3.7774,4$ star hotels $=3.8659$ and 3.9880 for 5 star hotels. The results suggested that the PEMP means for higher graded hotels ( 5 and 4 star) are greater than the means for the lower graded hotels (3-1 star). Next up is a test for the homogeneity of variances for hotel grade. The p-value for the Levene's test for homogeneity of variances is 0.001 , which is less than 0.05 . Thus, homogeneity of variance assumption is not met. Therefore the result from ANOVA cannot be used. Need to use a nonparametric test based on ranks. Based on the mean ranks, obviously, PEMP among five star hotel is higher compare to other star categories and four star hotel received second rank with compared to other categories. This is shown in Table 8.

Table 4: Descriptive statistics for proactive environmental management practices across size and grade

\begin{tabular}{lrrrr}
\hline \multicolumn{5}{c}{ Size of hotel } \\
& $\mathrm{5}$ & Std. Deviation & Std. Error \\
\hline Small & 52 & 3.5923 & .73106 & .10138 \\
Medium & 95 & 3.8611 & .63267 & .06491 \\
Large & 167 & 3.8240 & .63703 & .04929 \\
\hline \multicolumn{5}{c}{ Star grade of hotel (category) } \\
\hline 1 star & 33 & 3.5152 & .84636 & .14733 \\
\hline 2 star & 65 & 3.8200 & .48740 & .06046 \\
\hline star & 53 & 3.7774 & .63265 & .08690 \\
\hline 4 star & 77 & 3.8659 & .67968 & .07746 \\
\hline 5 star & 86 & 3.9880 & .66347 & .07154 \\
\hline
\end{tabular}

Table 5: Test of Homogeneity of Variances

\begin{tabular}{crrrrr}
\hline PEMP & Levene Statistic & df1 & \multicolumn{2}{c}{ df2 } & \multicolumn{1}{c}{ Sig. } \\
\hline Size of hotel & .780 & 2 & 311 & .459 \\
Star grade of hotel & 5.137 & 4 & 309 & .001 \\
\hline
\end{tabular}


Print ISSN: ISSN 2054-6424(Print), Online ISSN: ISSN 2054-6432(Online)

Table 6: Results of ANOVA

\begin{tabular}{lrrrrr}
\hline \multicolumn{7}{c}{ Size of hotel } \\
\hline PEMP & Sum of Squares & Df & Mean Square & F & Sig. \\
\hline Between Groups & 2.690 & 2 & 1.345 & 3.163 & .044 \\
Within Groups & 132.247 & 311 & .425 & & \\
\hline \multicolumn{7}{c}{ Star grade of hotel } \\
\hline Between Groups & 3.473 & 4 & .868 & 2.041 & .089 \\
Within Groups & 131.464 & 309 & .425 & & \\
\hline
\end{tabular}

Table 7: Post hoc test- Tukey test results

\begin{tabular}{llrrr}
\hline \multirow{2}{*}{ (I) hotel size } & $(\mathrm{J})$ hotel size & $\begin{array}{c}\text { Mean } \\
\text { Difference }(\mathrm{I}-\mathrm{J})\end{array}$ & \multicolumn{1}{c}{ Std. Error } & \multicolumn{1}{c}{ Sig. } \\
\hline \multirow{2}{*}{ Small } & medium & $-.26874^{*}$ & .11249 & .046 \\
& Large & -.23164 & .10356 & .067 \\
\multirow{4}{*}{ Large } & Small & $.26874^{*}$ & .11249 & .046 \\
& Large & .03710 & .08380 & .898 \\
& Small & .23164 & .10356 & .067 \\
& Medium & -.03710 & .08380 & .898 \\
\hline
\end{tabular}

Table 8: Nonparametric Kruskal Wallis Test - Mean Ranks and Significant

\begin{tabular}{llccc}
\hline & Hotel category & Mean Rank & Ranks & Significant \\
\hline $\begin{array}{l}\text { Proactive Environmental } \\
\text { Management Practices }\end{array}$ & 1 Star & 130.00 & 5 & 0.001 \\
& 2 Star & 155.53 & 3 \\
& 3 Star & 150.24 & 4 \\
& 4 Star & 159.45 & 2 \\
& 5 Star & 172.27 & 1 \\
\hline
\end{tabular}

\section{DISCUSSION AND CONCLUSION}

In this study, the adoption of proactive environmental management practices of hotels was measured using two dimensions: operational practices and system practices. The operational (technical) practice has reported highest mean score than the system (organizational) practices. The average mean shows that operational level environmental management practices receive greater importance. The overall mean score of proactive environmental management practices described that environmental proactivity of hotels varied between moderate extent and some extent scale and it suggests that hotels environmental proactivity shows somewhat proactive but not very strong. Independent sample t-test and one-way analysis of variance (ANOVA) were conducted to compare means of the adoption of proactive environmental management practices by ownership, hotel size, and star category. The results suggested that the proactive environmental management practices vary according to ownership of hotel. The chain hotels are very keen to implement PEMP than non - chain hotels. 
The proactive environmental practices among chain owned hotels is higher compare to independently owned hotels. Chain affiliation enables hotels access to information on environmental protection measures as well as sharing resources and taking advantage of economies of scale. Furthermore, the international chain hotels are more likely to implement environmental management practices due to the effects of economies of scale, marketing experience in markets where green differentiation is possible, and the possible transfer of environmental knowledge among affiliates (Wickramasinghe, 2016; Ayuso, 2006; Bohdanowicz, 2006 ; Carmona-Moreno et al., 2004; Alvarez Gil et al., 2001; Gonzalez \& Leon, 2001). Furthermore, the chain hotels always practice standardized hotel management which allows them to keep their reputation and taking advantage of economies of scale.

Moreover, the findings revealed that medium size hotels shows higher proactive environmental management than small and large hotels. The results found support for the notion that the firm size as one of the influencing factor of implementation of environmental practices, and hence it is considered as the significant determinant of the firm's choice of environmental management prcatices (Díaz-Garrido et al., 2016; Gonzalez-Benito \& Gonzalez-Benito, 2006). And concordance with results found by the extant environmental management literature, that larger firms being more proactive than smaller firms (Sharma, 2000; Alvarez Gil et al., 2001; Chan, 2005; Claver-Cortes et al., 2007; Gonzalez-Benito \& Gonzalez- Benito, 2006). The smaller firms have difficulties in adopting advanced environmental management programs due to lack of financial, human and other resources (Clark, 2000). These results may be explained through the concomitant of economies of scale and the existence of slack resources. The latter aspect reveals that firms need a minimum amount of financial and human resources to organize environmental management practices, because returns on environmental protection activities can only be achieved in the medium or long term (Carmona- Moreno et al., 2004).

Star classification of the hotels is also considered as a possible determinant of environmental orientation of hotels in the present analysis. The results explained that proactive environmental management practices are higher in five and four star hotel when it compare to other star categories. The results support the previous research where literature, higher level of star graded ( 5 to 4 star) hotels adopt more environmental practices than lower star hotel categories (Wickramasinghe, 2016).

\section{IMPLICATIONS}

The massive growth of the hotel industry and the contemporary issues relating to the natural environment has stressed the importance of implementation of proactive environmental management practices which go beyond legal compliances within the hotel industry. This will lead to the preservation of the environment and the success of the industry's future. Becoming knowledgeable of the ways in which adoption of proactive environmental management practices, its' benefit to the hotel industry and impact of contextual factors on environmental proactivity of hotels are important for the industry's leaders, clientele policy makers as well as researchers.

The purpose of this study was to assess the adoption of proactive environmental management practices in the hotel industry. Specially, the study to determine the present proactiveness of environmental management practices of hotels and to see whether the contextual factors such as ownership, size and grade are significantly related to the level of environmental proactivity. 
Therefore, the findings of this study provide implications in different ways in the form of theoretical implications, managerial implications and macro level implication such as changing and developing policies and regulations. This study presents practical implications for hotel companies and governing bodies for environmental initiatives. Currently, many chained hotels are making strong actions to promote environmental proactivity in order to differentiate themselves from their competitors. Moreover, medium and somewhat large hotels also practice considerable level of environmental proactivity than small and large hotels (Wickramasinghe, 2016). And five and four star hotels are stronger in the environmental proactivity than lower star graded hotels (3-1 star). Hence, government authority needs to make necessary arrangements to encourage hotels to be more responsive to environmental initiatives by introducing incentives, environmental rules and regulations. Besides, hotel's top-level managers such as GM, senior executives and owners of small hotels are the ones who make the final decision regarding business policies relating to environmental management of their hotels. Therefore, detailed and practical information about the feasibility and benefits of different environmental practices will enhance the hotel managers' act on environmental initiatives in a favorable manner. Local authorities and the industry should be act accordingly by providing necessary information and awareness for the relevant associations and people.

Also, the findings will help hoteliers to make future decisions regarding environmental strategies in the establishment. They can take necessary actions regarding environmental sustainability of their organization, including, provide training and information for managers about the importance of environmental management, development of environmental policies and procedures, environmental monitoring systems and provision of environmental management incentive system for enhanced environmental initiatives. The study also provides benefits to the Sri Lankan tourism industry. The eventual findings provide comprehensive information on adoption of proactive environmental management practices in star grade hotels in Sri Lanka. This information is helpful at different levels, namely managerial level, industry level and policy making level as to make decisions on initiating implementation of environmental management practices. Overall, the results are important for hoteliers, local, regional and global associations and policy makers.

\section{LIMITATION AND FUTURE RESEARCH}

Event though, the study has significant contribution to the field of environmental management and hotel industry, it has some limitations. The study has discovered only the environmental commitment of "star grade hotels", and hence the findings may not be generalizable to other accommodation establishments in Sri Lanka. To reproduce these findings, other types of accommodation and more industries covered by future studies could be broadened. This might also involve undertaking comparative studies across various countries in the region. Furthermore, this study used only three contextual factors namely size of the hotel, ownership and grade but there are some other factors that may influence on adoption of proactive environmental management practices such as age of hotel, financial positions and geographical location. This study is of cross sectional type and hence, the study does not shed light on changes in environmental practices and strategies over time. Therefore, it is anticipated that other researchers will be able to study across longer periods of time as a longitudinal study in the future to validate the conclusions regarding the adoption of proactive environmental 
management practices in the hotel industry. The study mainly applied positivist research methodology with survey data collection method which primarily relies on top managers' selfreported data to measure study constructs. This would not be the best reality and alternatively, the same research problem can be addresses in neo- positive research domain of mix method (quantitative study followed by a qualitative).

\section{REFERENCES}

Aragon-Correa, J. A. (1998). Strategic proactivity and approach to the natural environment. Academy Management Journal, 41(5), 556-567.

Álvarez Gil, M. J., Burgos Jiménez, J., \& Céspedes Lorente, J. J. (2001). An analysis of environmental management, organizational context and performance of Spanish hotels. Omega, 29, 457-471.

Ayuso, S. (2006). Adoption of voluntary environmental tools for sustainable tourism: analysing the experience of Spanish hotels. Corporate Social Responsibility and Environmental Management, 13(4), 207- 220.

Banerjee, S. B., Iyer, E. S., \& Kashyap, R. K. (2003). Corporate Environmentalism: Antecedents and Influence of Industry Type. Journal of Marketing, 67(2), 106-122.

Baumgartner, R. J., \& Rauter, R. (2017). Strategic perspectives of corporate sustainability management to develop a sustainable organization. Journal of Cleaner Production, 140, 81-92.

Brown, J.R., \& Dev, C.S. (1999). Looking beyond RevPar. Cornell Hotel and Restaurant, Administration Quarterly, 40(2), 23-33.

Bohdanowicz, P. (2006).Environmental awareness and initiatives in the Swedish and Polish hotel industries-survey results. International Journal of Hospitality Management, 25 (4), 662-682.

Buysse, K., \& Verbeke, A. (2003). Proactive environmental strategies: A stakeholder management perspectives. Strategic Management, 24(5), 453-470.

Carmona-Moreno,E., Céspedes-Lorente ,J., \& De Burgos-Jiménez,J. (2004). Environmental strategies in Spanish hotels: contextual factors and performance, The Service Industries Journal, 24(3), 101-130.

Chan, W.W. (2005). Partial analysis of the environmental costs generated by hotels in Hong Kong. Tourism Management, 24(4), 517-531.

Chou, C. J. (2014).Hotels' environmental policies and employee personal environmental beliefs: Interactions and outcomes, Tourism Management, 40,436-446.

Clark, G. (2000), "Developing better systems for communications: environmental best practice in small business", in Hillary, R. (Ed.), Small and Medium-sized Enterprises and the Environment, Greenleaf, Sheffield.

Claver-Cortés, E., Molina-Azorin, J. F., Pereira-Moliner, J., \& López-Gamero, M. D. (2007). Environmental strategies and their impact on hotel performance. Journal of Sustainable Tourism, 15(6), 663-679.

Díaz-Garrido, E., Martín-Peña, M. L., \& Sánchez-López, J. M. (2016). Determinants of environmental strategy in the automotive sector: Analysis of key factors. International Journal of Sustainable Transportation, 10(5), 430-440.

Erdogan, N., \& Tosun, C. (2009). Environmental performance of tourism accommodations in the protected areas: Case of Goreme Historical National Park. International Journal of Hospitality Management, 28(3), 406-414. 
Etzion, D. (2007). Research on organizations and the natural environment, 1992-present: A review. Journal of Management, 33(4), 637-664.

Farrell, B. H., \& Runyan, D. (1991). Ecology and tourism. Annals of Tourism Research, 18(1), 26-40.

Florida, R. (1996). Lean and green: the move to environmentally conscious manufacturing. California management review, 39(1), 80-105.

González-Benito,J \& González-Benito,O. (2006). A Review of Determinant Factors of Environmental Proactivity. Business Strategy and the Environment, 15(2), 87-102.

González, M., \& León, C. J. (2001). The adoption of environmental innovations in the hotel industry of Gran Canaria. Tourism Economics, 7(2), 177-190.

Gustafsson, S., Hermelin, B., \& Smas, L. (2019). Integrating environmental sustainability into strategic spatial planning: the importance of management. Journal of Environmental Planning and Management, 62(8), 1321-1338.

Hart, S. L., \& Dowell, G. (2011). Invited editorial: A natural-resource-based view of the firm: Fifteen years after. Journal of management, 37(5), 1464-1479.

Liu, L. (2019). Top Management Characteristics, Green Supply Chain Management and Corporate Performance. Journal of Human Resource and Sustainability Studies, 7(1), 55-71.

Lu, J., \& Nepal, S. K. (2009). Sustainable tourism research: An analysis of papers published in the Journal of Sustainable Tourism. Journal of Sustainable Tourism, 17(1), 5-16.

Marchi, V. D., Maria, E. D., \& Micelli, S. (2013). Environmental strategies, upgrading and competitive advantage in global value chains. Business strategy and the environment, 22(1), 62-72.

Mensah, I. (2006). Environmental management practices among hotels in the greater Accra region. International Journal of Hospitality Management, 25, 414-431

Mbasera, M., du Plessis, E., Saayman, M., \& Kruger, M. (2018). Determining the impact of green management policies on hotel performance: A manager's perspective.

Molina-Azor'n, J.F., Claver-Corte's,E., Pereira-Moliner, J., \& Jose' Tar, J. (2009). Environmental practices and firm performance: an empirical analysis in the Spanish hotel industry. Journal of Cleaner Production, 17(1), 516-524.

Pallant, J. (2016). SPSS Survival Guide. Step by step guide to data analysis using IBM SPSS (3rd ed.), Open University press, McGraw - Hill Education, England.

Park, J., Jeong Kim, H., \& McCleary, K. W. (2014). The impact of top management's environmental attitudes on hotel companies' environmental management. Journal of Hospitality \& Tourism Research, 38(1), 95-115.

Russo, M. V., \& Fouts, P. A. (1997). A resource-based perspective on corporate environmental performance and profitability. Academy of management Journal, 40(3), 534-559.

Russo, A., \& Perrini, F. (2010). Investigating stakeholder theory and social capital: CSR in large firms and SMEs. Journal of Business ethics, 91(2), 207-221.

Scholz, P., \& Voracek, J. (2016). Organizational culture and green management: innovative way ahead in hotel industry. Measuring Business Excellence, 20(1), 41-52.

Sharma, S. (2000). Managerial interpretations and organizational context as predictors of corporate choice of environmental strategy. Academy of Management, 43(4), 681-697.

Singh, N., Jain, S., \& Sharma, P. (2014). Determinants of proactive environmental management practices in Indian firms: an empirical study. Journal of Cleaner Production, 66, 469478. 
Testa,F., Gusmerottia, N.M., Corsini,F., Passetti, E., \& Iraldo, F. (2015). Factors Affecting Environmental Management by Small and Micro Firms: The Importance of Entrepreneurs' Attitudes and Environmental Investment. Corporate Social Responsibility and Environmental Management, (wileyonlinelibrary.com) DOI: 10.1002/csr.1382c.

Vachon, S., \& Klassen, R. D. (2006). Extending green practices across the supply chain: the impact of upstream and downstream integration. International Journal of Operations \& Production Management, 26(7), 795-821.

Wickramasinghe, C. (2016). Good Environmental Management Practices in the Hotel Industry in Sri Lanka: Determinants and Barriers. 'Talking Economics', the blog of the Institute of Policy Studies of Sri Lanka (IPS), Sri Lanka's apex socio-economic policy think tank.

The World Travel and Tourism Council (WTTC), 2018.

United Nations Environmental Programme (UNEP), 2018.

United Nations World Tourism Organization (UNWTO), 2018.

Zikmund, W.G. (2003) Business Research Methods, (7th edn), Thompson South-Western: Ohio 